\title{
Duration of effect of single-dose inhaled fluticasone propionate on AMP-induced bronchoconstriction
}

\author{
B. Luijk*, R.D. Kempsford*, A.M. Wright* , P. Zanen*, J-W.J. Lammers*
}

\begin{abstract}
Duration of effect of single-dose inhaled fluticasone propionate on AMP-induced bronchoconstriction. B. Luijk, R.D. Kempsford, A. M. Wright, P. Zanen, J-W.J. Lammers. (C) ERS Journals Ltd 2004.
\end{abstract}

ABSTRACT: Airway hyperresponsiveness induced by adenosine-5' ${ }^{\prime}$-monophosphate (AMP) is regarded as a reliable model for allergic asthma and for the evaluation of anti-asthmatic drugs. Single-dose inhaled corticosteroids (ICS) are known to be protective in this model, but the duration of action of these drugs in this model has never been studied.

The duration of ICS protection was determined by administration of single-dose fluticasone propionate (FP; $1,000 \mu \mathrm{g})$ up to $26 \mathrm{~h}$ before AMP challenge. A randomised, double-blind, placebo-controlled, four-way crossover study was performed in 13 mild asthmatics (mean \pm SD predicted forced expiratory volume in one second (FEV1) $98 \pm 7 \%$ ). Each subject received placebo and FP (at 26, 14 or $2 \mathrm{~h}$ prior to the AMP challenge). Furthermore, the marker exhaled nitric oxide (eNO) was studied after administration at these time points to investigate whether eNO also demonstrates the duration of action of ICS.

The doubling concentrations difference (DCD) of AMP causing a 20\% fall in FEV1, when FP was administered 26,14 or 2 h prior to challenge, was significantly increased as compared with placebo: DCD $(95 \%$ confidence interval) at $26 \mathrm{~h}, 0.73(0.20-1.26)$, $\mathrm{p}=0.008 ; 14 \mathrm{~h}, 1.50(0.99-2.01), \mathrm{p}<0.001 ;$ and $2 \mathrm{~h}, 2.89(2.37-3.40), \mathrm{p}<0.001$. However, eNO was not significantly affected at these time points.

In conclusion, a single dose of $1,000 \mu \mathrm{g}$ inhaled fluticasone propionate protects against adenosine-5'-monophosphate airway hyperresponsiveness up to $26 \mathrm{~h}$ after dosing. This study suggests that adenosine-5' - -monophosphate challenge can be used as a sensitive marker to study the duration of action of inhaled corticosteroids.

Eur Respir J 2004; 23: 559-564.
*Dept of Pulmonary Diseases, Heart Lung Center Utrecht, University Medical Center Utrecht, the Netherlands. " GlaxoSmithKline, Research and Development, Greenford, UK.

Correspondence: J-W.J. Lammers

Dept of Pulmonary Diseases

Heart-Lung Center Utrecht

University Medical Center Utrecht

Heidelberglaan 100

3584 CX Utrecht

The Netherlands

Fax: 31302505415

E-mail: j.w.j.lammers@hli.azu.nl

Keywords: Adenosine-5'-monophosphate airway hyperresponsiveness

asthma

exhaled nitric oxide

fluticasone propionate

Received: April 172003

Accepted after revision: November 242003

This study was funded by GlaxoSmithKline, UK.
Inhaled corticosteroids (ICS) are commonly used as protective anti-inflammatory drugs in the treatment of asthma [1]. The anti-inflammatory effects of ICS can be shown by demonstrating their influence on airway hyperresponsiveness (AHR), which is one of the characteristics of chronic airway inflammation in asthma [2].

AHR can be measured using inhalation of direct bronchoconstrictors (e.g. histamine or methacholine) or indirect agents such as adenosine-5'-monophosphate (AMP) [3]. Inhaled AMP functions, at least in part, through activation of mast cells that release the secondary bronchoconstricting mediators leukotrienes and histamine [4, 5]. These indirect airway challenges appear to be a better surrogate marker of the ICS-induced anti-inflammatory effects than direct challenges $[3,6,7]$.

Recently, two studies demonstrated a rapidly induced protective effect when a single dose of an ICS was administered prior to an indirect challenge. A protective effect of fluticasone propionate (FP) against AMP challenge was observed within $2 \mathrm{~h}$ of administration and a protective effect of budesonide against hypertonic saline challenge was found within $6 \mathrm{~h}$ of administration $[8,9]$. Interestingly, the study with single-dose inhaled FP demonstrated protection towards AMP-AHR but not after direct challenge with histamine. Therefore, AMPinduced bronchoconstriction appears to be a rapid model to evaluate the anti-inflammatory effect, the direct potency and thus efficacy of single-dose ICS in asthmatics.
However, currently no information exists on the duration of effect of a single inhaled dose of FP on AHR. This duration of effect could then be used in comparative studies with other ICS.

Furthermore, the current authors were interested in whether the AMP challenge is solely affected by a single dose of ICS or whether another surrogate marker of airway inflammation is as sensitive as AMP-AHR to show this rapid anti-inflammatory response. This was the rationale for studying eNO, which has also been shown to be a sensitive marker of ICS-induced anti-inflammatory effects [10].

Therefore, the aim of this study was to investigate the duration of effect of a single dose of inhaled FP by using the AMP-challenge model and to compare AMP-AHR with eNO as surrogate markers of airway inflammation. A relatively high optimal dose of $1,000 \mu \mathrm{g} \mathrm{FP}$, as indicated by the results of KETCHELL et al. [8], was studied to determine the duration of protection after a single dose of FP.

\section{Materials and methods}

\section{Subjects}

Thirteen nonsmoking, atopic subjects with intermittent or mild persistent asthma, according to the GINA (Global Initiative on Asthma) guidelines [11], were included in the 
study. Presence of atopy was confirmed by at least one positive skin-prick test. At screening and during treatment periods, all subjects' asthma was stable and demonstrated a provocation concentration of AMP causing a 20\% fall in forced expiratory volume in one second (FEV1) (AMP-PC20) of $<50 \mathrm{mg} \cdot \mathrm{mL}^{-1}$ at screening. After a run-in period of 7 days, a second AMP challenge was performed to confirm stability of the AMP-PC20. If the AMP-PC20 was not within 1.5 doubling concentrations from the screening value the subject was excluded from further participation in the study. Every patient had a baseline FEV1 of $>70 \%$ predicted according to European Respiratory Society values [12]. ICS and other antiasthmatic medications were not allowed 4 weeks before the screening visit and throughout the study, except for shortacting $\beta_{2}$-agonists, which had to be withheld $12 \mathrm{~h}$ before each visit. Subjects who used oral corticosteroids within 8 weeks before entering the study and throughout the study were also excluded. Caffeine-containing food and beverages and alcohol were not allowed $8 \mathrm{~h}$ before and during each treatment period.

The study was approved by the medical ethics committee of the University Medical Center Utrecht (Utrecht, the Netherlands) and all patients gave their written informed consent.

\section{Study design}

All subjects underwent four treatment periods according to a randomised, double-blind, crossover, placebo-controlled design. The duration and efficacy of a single-dose ICS was determined by administration of $1,000 \mu \mathrm{g}$ FP from a four blister diskhaler device (GlaxoSmithKline, Stevenage, UK) in each treatment period. There were four, 2-day treatment periods. Each subject received four different treatments: three active (FP) and one with placebo only. For the active treatments, single-dose FP 1,000 $\mu \mathrm{g}$ was administered 26, 14 or $2 \mathrm{~h}$ prior to AMP challenge. For each active treatment period, matching placebo (lactose powder) was administered at the other time points to maintain the treatment blinding. The placebo-alone treatment was lactose powder at 26, 14 and $2 \mathrm{~h}$ pre-AMP challenge. There was a washout period of at least 1 week between each treatment. During the study, only salbutamol was permitted to inhale as rescue medication if needed. Seven to 14 days after the final treatment period, subjects returned to the hospital for a post-study final visit for safety blood tests and to establish stable asthmatic symptoms.

\section{AMP challenge}

AMP was inhaled in doubling concentrations at 5-min intervals in the range $0.04-320 \mathrm{mg} \cdot \mathrm{mL}^{-1}$, according to a standardised challenge protocol to determine AMP-PC20 as previously described $[13,14]$. FEV1 was measured in duplicate at 30 and $90 \mathrm{~s}$ after 2-min tidal breathing from a calibrated $\left(0.13 \mathrm{~mL} \cdot \mathrm{min}^{-1}\right.$ ) nebuliser (model 646; Devilbiss Inc., Somerset, PA, USA) while the nose was clipped. During the doubleblind period, inhaled AMP was given until the FEV1 fell by $\geqslant 20 \%$ from baseline or when the maximum concentration of AMP was inhaled. AMP (Sigma-Aldrich, St. Louis, MO, USA) was dissolved in saline $(0.9 \%)$ solution to produce the doubling concentrations.

\section{Forced expiratory volume in one second measurements}

FEV1 measurements were recorded with the same mobile bi-directional digital spirometer (Sensorloop; SensorMedics
Corp, Yorba Linda, CA, USA) during treatment periods at pre-dose at day 1 (i.e. before the first of the three doses) and pre-dose at day 2 (i.e. before the last of the three doses, FEV1 only), pre-challenge (i.e. $2 \mathrm{~h}$ after the last administered dose), and regular time points during AMP-challenge protocol.

\section{Exhaled nitric oxide}

Exhaled nitric oxide (eNO) was measured in parts per billion, according to the American Thoracic Society standards, with a calibrated chemiluminescence analyser (type CLD 77 AM; Eco Physics, Duernten, Switzerland) with a flow rate of $250 \mathrm{~mL} \cdot \mathrm{s}^{-1}$ [15]. Exhalations into a NO reader were repeated three times and then the overall mean was calculated. eNO was measured at similar time points to FEV1, except the pre-dose value at day 2 . The eNO recordings were always obtained before the FEV1 values.

\section{Measurement of plasma fluticasone propionate levels}

Blood samples were taken for determination of plasma FP concentrations to demonstrate the absence of circulating FP prior to dosing and to determine the plasma FP concentrations at AMP challenge. Blood samples $(5 \mathrm{~mL})$ were collected before the first dose and immediately pre-AMP challenge $(2 \mathrm{~h}$ after the last dose was inhaled), and placed immediately on ice and centrifuged at $1,000 \times g$ for $10 \mathrm{~min}$ at $4^{\circ} \mathrm{C}$. The plasma supernatant was stored in tubes at $-70^{\circ} \mathrm{C}$ until further processing. FP was then quantified in plasma by automated solid-phase extraction followed by liquid chromatography tandem mass spectrometry (Applied Biosystems API3000; Applied Biosystems, Warrington, UK). The limit of quantification was $10 \mathrm{pg} \cdot \mathrm{mL}^{-1}$.

\section{Data analysis}

The planned sample size of 12 subjects was predicted to have $80 \%$ power to detect a ratio for AMP-PC20 of 2.4 between any two of the treatment groups, assuming a withinsubject SD on the $\log _{\mathrm{e}}$ scale of 0.77 and a significance level of $5 \%$. This ratio is equivalent to a difference of 1.26 doubling concentrations difference (DCD) between treatment groups. The AMP-PC20 and eNO measurements were analysed using analysis of variance. The following factors were included in the models: subject, period and treatment group. The data were $\log$ transformed prior to analyses. For the PC20 data, differences and 95\% confidence intervals (CI) between treatment groups were presented in terms of DCDs. For the $\mathrm{NO}$ data, the comparisons were calculated in terms of a ratio (eNO ratio) and 95\% CI (FP/placebo). A ratio of 1 would indicate no effect of FP compared with placebo. All other data were expressed as (geometric) means (95\% CI) unless otherwise stated. Differences were considered to be statistically significant if the p-level was $<0.05$.

\section{Results}

\section{Subjects}

Subject characteristics are listed in table 1. The AMP-AHR of the included subjects was stable before starting the four treatment periods (individual AMP-PC20 values were within the above-mentioned 1.5 DCD). The mean AMP-PC20 difference between screening and run-in period expressed in $\mathrm{DCD} \pm$ SD was $0.27 \pm 0.71$. 
Table 1. - Subject characteristics of included mild asthmatic patients

\begin{tabular}{|c|c|c|c|c|c|c|c|}
\hline \multirow[t]{2}{*}{ Subject } & \multirow[t]{2}{*}{ Sex } & \multirow[t]{2}{*}{ Age yrs } & \multirow[t]{2}{*}{ Atopy ${ }^{\#}$} & \multirow[t]{2}{*}{ FEV1 \% pred } & \multirow[t]{2}{*}{ eNO ppb } & \multicolumn{2}{|c|}{ AMP-PC20 mg $\cdot \mathrm{mL}^{-1}$} \\
\hline & & & & & & Screening & Run-in \\
\hline 1 & M & 22 & $\mathrm{H}$ & 91 & 24.87 & 1.77 & 0.85 \\
\hline 2 & $\mathrm{M}$ & 19 & $\mathrm{H}, \mathrm{C}$ & 99 & 15.83 & 14.28 & 20.00 \\
\hline 3 & M & 24 & $\mathrm{H}, \mathrm{G}, \mathrm{C}$ & 89 & 10.24 & 5.10 & 2.17 \\
\hline 4 & $\mathrm{~F}$ & 21 & H,G & 99 & 21.13 & 3.00 & 1.65 \\
\hline 5 & $\mathrm{~F}$ & 20 & $\mathrm{H}, \mathrm{G}, \mathrm{C}$ & 99 & 8.68 & 34.72 & 50.36 \\
\hline 6 & $\mathrm{~F}$ & 22 & $\mathrm{H}, \mathrm{C}$ & 92 & 27.70 & 2.08 & 1.73 \\
\hline 7 & M & 22 & $\mathrm{H}$ & 105 & 16.92 & 9.16 & 11.87 \\
\hline 8 & M & 24 & $\mathrm{H}, \mathrm{G}$ & 92 & 10.99 & 10.84 & 7.78 \\
\hline 9 & M & 20 & $\mathrm{H}, \mathrm{G}, \mathrm{C}$ & 107 & 38.32 & 16.34 & 16.99 \\
\hline 10 & $\mathrm{~F}$ & 23 & $\mathrm{H}, \mathrm{G}$ & 107 & 41.54 & 14.14 & 9.33 \\
\hline 11 & $\mathrm{~F}$ & 21 & $\mathrm{H}, \mathrm{C}$ & 87 & 30.38 & 3.61 & 7.43 \\
\hline 12 & $\mathrm{~F}$ & 24 & $\mathrm{H}, \mathrm{G}, \mathrm{C}$ & 98 & 17.41 & 5.00 & 3.47 \\
\hline 13 & M & 22 & $\mathrm{H}, \mathrm{C}$ & 105 & 12.55 & 4.91 & 2.46 \\
\hline Mean $\pm \mathrm{SD}$ & & $21.8 \pm 1.6$ & & $97.7 \pm 7.0$ & $18.87(50)$ & $6.72(94)$ & $5.56(129)$ \\
\hline
\end{tabular}

M: male; F: female; FEV1: forced expiratory volume in one second; eNO: exhaled nitric oxide; AMP-PC20: provocation concentration of AMP causing a $20 \%$ fall in FEV1. ${ }^{\#}$ : atopy defined as positive skin-prick tests for house dust mite $(\mathrm{H})$, grass $(\mathrm{G})$ and cat $(\mathrm{C})$; ${ }^{\text {: }}$ : geometric mean (coefficient of variation \%)

Due to incorrect diskhaler use, one subject received the same treatment twice (FP $14 \mathrm{~h}$ before the challenge). Although this subject completed the trial, an additional subject was recruited. Data from all 13 subjects were used in the analyses.

\section{Effect of single-dose inhaled fluticasone propionate on forced expiratory volume in one second}

During the four treatment periods with either active FP at the three different FP administration time points or the placebo treatment, no differences were found in pre-dose and post-dose FEV1 values (FP at 26 h: $3.88 \mathrm{~L}(3.40-4.43)$; FP at $14 \mathrm{~h}: 3.93 \mathrm{~L}$ (3.47-4.44); FP at $2 \mathrm{~h}: 3.83 \mathrm{~L}$ (3.38-4.34); and during placebo: $3.76 \mathrm{~L}$ (3.32-4.27)). Furthermore, no differences in baseline FEV1 values were observed between the four treatment periods during the study.

\section{Effect of single-dose inhaled fluticasone propionate on AMP-PC20}

The individual AMP-PC20 data are given in table 2. The AMP-PC20 after FP administration was statistically significantly different from placebo treatment at all three time points. The DCD (95\% CI; FP to placebo) were as follows: 0.73 (0.20-1.26), $\mathrm{p}=0.008 ; 1.50$ (0.99-2.01), $\mathrm{p}<0.001$; and 2.89 (2.37-3.40), $\mathrm{p}<0.001$, for the $26 \mathrm{~h}, 14 \mathrm{~h}$ and $2 \mathrm{~h}$ groups, respectively, as shown in figure la and table 3. The AMPPC20 measured at $2 \mathrm{~h}$ after FP inhalation was also significantly higher than the AMP-PC20 values at 26 and $14 \mathrm{~h}$, respectively (DCD 2-26 h: 2.16 (1.63-2.68), $\mathrm{p}<0.001$; 2-14 h: $1.39(0.88-1.89), \mathrm{p}<0.001)$, and a significant difference between 26 and $14 \mathrm{~h}$ time points of FP administration (DCD: $0.77(0.24-1.30), \mathrm{p}=0.005)$ was observed. Although there is one clear upper outlier in the AMP-PC20 dataset at $26 \mathrm{~h}$ FP administration, this outlier did not have a large influence on the results. An analysis was performed excluding this subject and the difference at $26 \mathrm{~h}$ was still statistically significant.

The effect of single-dose fluticasone propionate on exhaled nitric oxide

In table 4, the geometric means and ratios for the eNO values for the four treatment groups are presented.

Table 2. - The individual provocation concentration of AMP causing a $20 \%$ fall in forced expiratory volume in one second values during the four treatment periods (placebo, 26, 14 and $2 \mathrm{~h}$ ) in 13 asthmatics

\begin{tabular}{lrrrr}
\hline Subject & Placebo & $26 \mathrm{~h}$ & $14 \mathrm{~h}$ & $2 \mathrm{~h}$ \\
\hline 1 & 0.39 & 0.72 & 1.03 & 2.21 \\
2 & 49.25 & 80.00 & 74.64 & 320.00 \\
3 & 2.13 & 5.35 & 8.51 & 21.77 \\
4 & 3.66 & 6.83 & 6.48 & 16.22 \\
5 & 32.05 & 209.55 & 320.00 & 17.79 \\
6 & 1.71 & 5.21 & 85.90 & 13.53 \\
7 & 9.33 & 20.80 & 13.47 & 74.22 \\
8 & 6.45 & 6.48 & 97.04 & 160.00 \\
9 & 20.87 & 33.25 & 36.77 & 40.00 \\
10 & 18.11 & & 13.56 & 92.55 \\
11 & 9.84 & 8.49 & 11.22 & 68.77 \\
13 & 10.00 & 13.53 & 21.47 & 84.16 \\
Geomean $(95 \% \mathrm{CI})$ & 18.72 & 7.76 & $21.0(8.41-49.47)$ & $54.9(24.14-127.7)$ \\
\hline
\end{tabular}

CI: confidence interval. 

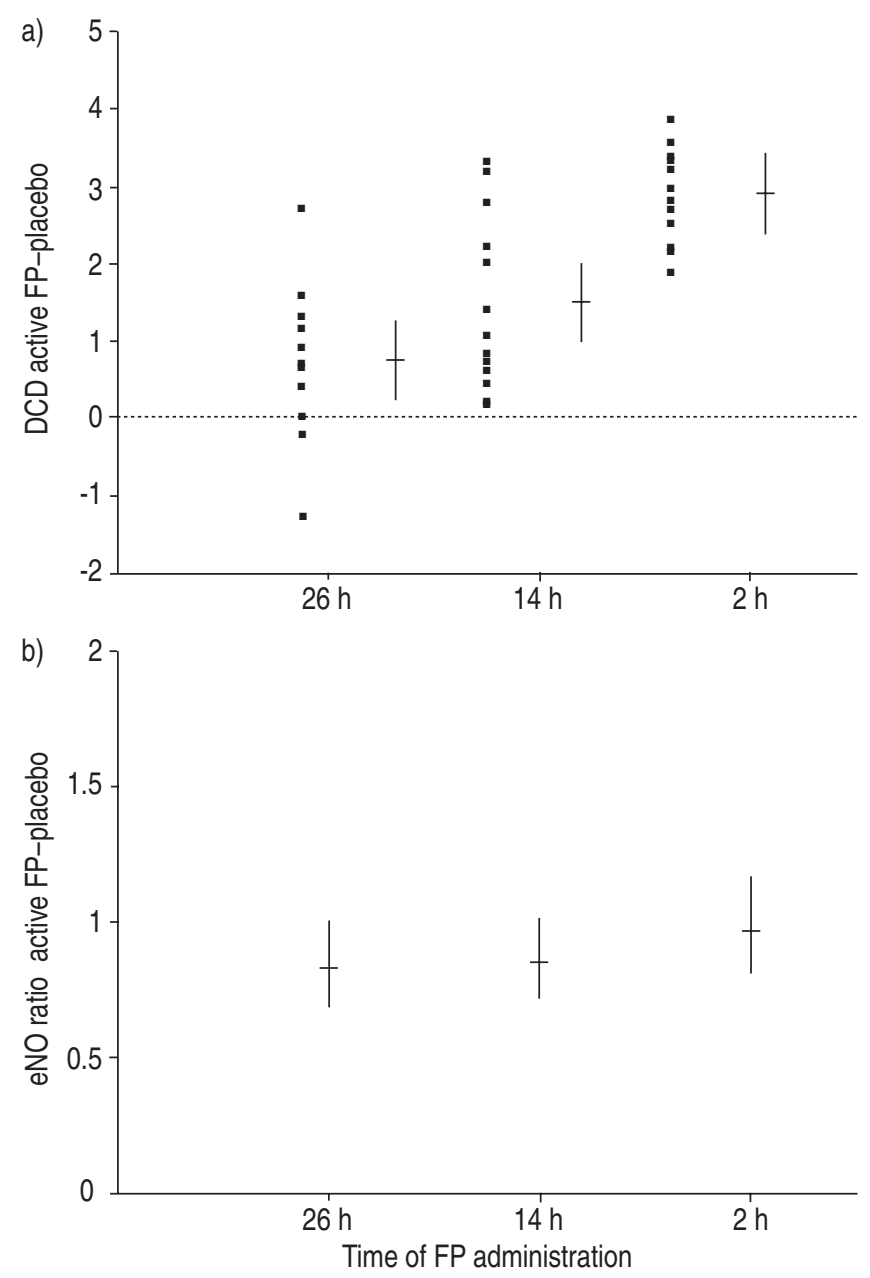

Fig. 1.-a) Doubling concentrations difference (DCD) and 95\% confidence intervals $(\mathrm{CI})$ of the provocative concentration of AMP causing a $20 \%$ fall in the forced expiratory volume in one second (AMP-PC20) with the administered active fluticasone propionate (FP) treatment compared with placebo at the indicated time points. b) Ratio and $95 \%$ CI of exhaled nitric oxide (eNO) with the administered active FP treatment compared with placebo at the indicated time points.

There was a nonsignificant decrease in pre-challenge eNO values when FP was administered 26 and $14 \mathrm{~h}$ prior to the AMP challenge, with a lowest ratio of $0.83(0.68-1.01, p=0.06)$

Table 3.-Geometric means and doubling concentration differences (DCD) of the provocation concentration of AMP causing a $20 \%$ fall in forced expiratory volume in one second (AMP-PC20) values during placebo and fluticasone propionate (FP) administered 26, 14 and $2 \mathrm{~h}$ before AMP challenge

\begin{tabular}{lccr}
\hline $\begin{array}{l}\text { Treatment } \\
\text { group }\end{array}$ & $\begin{array}{c}\text { AMP-PC20 } \\
\mathrm{mg} \cdot \mathrm{mL}^{-1}\end{array}$ & DCD (CI) & p-value \\
\hline Placebo & 7.4 & & \\
$\begin{array}{l}\text { FP 1,000 } \mu \mathrm{g} \\
26 \mathrm{~h}\end{array}$ & 12.3 & $0.73(0.20-1.26)$ & 0.008 \\
$14 \mathrm{~h}$ & 21.0 & $1.50(0.99-2.01)$ & $<0.001$ \\
$2 \mathrm{~h}$ & 54.9 & $2.89(2.37-3.40)$ & $<0.001$ \\
\hline
\end{tabular}

CI: confidence interval; ${ }^{\#}$ : for the active treatment groups, the length of time between the dose and AMP challenge is indicated; ${ }^{\circ}$ : adjusted for period effects; ${ }^{+}$: between active treatment group and placebo expressed in terms of doubling concentrations of AMP (see fig. 1a); $\$$ : for pairwise comparisons with placebo.
Table 4.-Geometric means and ratio of the pre-challenge exhaled nitric oxide (eNO) concentrations during placebo and fluticasone propionate (FP) administered 26, 14 and $2 \mathrm{~h}$ before AMP challenge

\begin{tabular}{lccc}
\hline Treatment group $^{\#}$ & eNO ppb & Ratio $^{+}(\mathrm{CI})$ & p-value $^{\S}$ \\
\hline Placebo & 18.7 & & \\
FP 1,000 $\mu \mathrm{g}$ & & & \\
26 h & 15.5 & $0.83(0.68-1.01)$ & 0.06 \\
$14 \mathrm{~h}$ & 16.0 & $0.85(0.71-1.03)$ & 0.09 \\
$2 \mathrm{~h}$ & 18.2 & $0.97(0.80-1.17)$ & 0.75 \\
\hline
\end{tabular}

CI: confidence interval. ${ }^{\#}$ : for the active treatment groups, the length of time between the dose and AMP challenge is indicated; $"$ : geometric means in parts per billion (ppb) adjusted for period effects; ${ }^{+}$: between active treatment group and placebo; ${ }^{\S}$ : for pairwise comparisons with placebo.

at $26 \mathrm{~h} \mathrm{FP}$ administration compared to placebo (table 4 and fig. 1b).

\section{Plasma fluticasone propionate levels}

Pre-challenge plasma FP concentrations were below the limit of quantification in the placebo treatment period and in all the pre-treatment samples. Plasma FP levels immediately prior to AMP challenge (i.e. $2 \mathrm{~h}$ post-dose) were detectable in all subjects when FP was given $14 \mathrm{~h}$ (median $32.8 \mathrm{pg} \cdot \mathrm{mL}^{-1}$ (range 16.8-57.4)) and $2 \mathrm{~h}\left(147.1 \mathrm{pg} \cdot \mathrm{mL}^{-1}(65.8-225.0)\right)$ before the AMP challenge. When FP was administered $26 \mathrm{~h}$ prior to the AMP challenge, plasma FP levels were below the limit of quantification in half the subjects, whereas the other subjects demonstrated a median of $15.3 \mathrm{pg} \cdot \mathrm{mL}^{-1}(10.2-20.7)$. There was no correlation between DCD AMP-PC20 improvement and the 2-h post-dose plasma FP levels at the time points studied.

\section{Discussion}

In this study, the authors found that a single dose of $1,000 \mu \mathrm{g}$ inhaled $\mathrm{FP}$, administered 26,14 or $2 \mathrm{~h}$ prior to challenge, protected against AMP-induced bronchoconstriction. A single dose of $1,000 \mu \mathrm{g}$ FP given at these time points did not appear to significantly change pre-AMP challenge FEV1 or eNO levels.

The findings of AMP-PC20 improvement are in agreement with previous studies demonstrating similar improvement after repeat-dose or single-dose inhalation of ICS when the last dose was administered shortly before challenge [8, 9, 16, 17]. This early protective effect of FP against AMP challenge is also consistent with the recent findings of PROSPERINI et al. [7], who showed that AHR to inhaled AMP promptly detected inflammatory changes of the asthmatic airways as early as the first week of treatment with budesonide and that AMP-PC20 returned to near baseline levels as early as the first week of treatment [7]. In addition, a single dose of ICS administered just before an allergen challenge inhibited the late asthmatic response [18]. In the present study, the duration of anti-inflammatory effects of single-dose FP was directly assessed by altering the FP-AMP challenge interval.

ICS are known for their topical anti-inflammatory effects and inhaled FP in particular has a highly favourable topical efficacy compared with systemic safety [19]. This direct topical effect of ICS is supposed to be responsible for the acute clinical effect on FEV1 as soon as $2 \mathrm{~h}$, as demonstrated in a previous study in acute severe asthma [20]. This FEV1 improvement was also shown $6 \mathrm{~h}$ after single high-dose ICS 
treatment with budesonide $(2,400$ and 1,600 $\mu \mathrm{g}$, respectively) $[9,21]$. However, no effect was found on the FEV1 $2 \mathrm{~h}$ after administration of a single dose of $1,000 \mu \mathrm{g}$ FP in the study by KETCHELl et al. [8], which is comparable to the present results at $2 \mathrm{~h}$, or at the 14 and $26 \mathrm{~h}$ time points. This may be due to the current mild stable disease of the asthmatics that were studied. Moreover, ICS induce an acute anti-inflammatory effect on AHR measured by indirect challenges [8, 9]. The improvement on AMP-AHR after FP inhalation up to $26 \mathrm{~h}$ found in this study may be due to local high affinity towards the glucocorticoid receptor of FP in the airways after inhalation and by the long half-life of the FP active steroid receptor complex of $>10 \mathrm{~h}[22,23]$. The optimal FP protection on AMP-induced bronchoconstriction was demonstrated in a recent abstract, with the highest effect when FP was administered $4 \mathrm{~h}$ prior to an AMP challenge and not at the previously mentioned $2 \mathrm{~h}$ [24]. In addition, the decreasing anti-inflammatory response measured by AMP-AHR up to $26 \mathrm{~h}$ was associated with nondetectable FP plasma levels in half of the subjects and, without correlation, with the doubling concentration of the AMP-PC20 difference at the three time points, which further supports the notion that this duration of action is a sustained topical FP effect rather than a systemic anti-inflammatory effect [19].

Recently, several mechanisms have been proposed regarding the acute protective effect of single-dose ICS on AMPinduced bronchoconstriction by influencing the adenosine receptors that may play a role in airway inflammation [8]. The inhibition of adenosine receptor activity by ICS after binding to the glucocorticoid receptor on the membrane is suggested to be rapidly induced by nongenomic antiinflammatory effects within minutes and by genomic antiinflammatory effects within hours [8,25]. It is likely that both the nongenomic and genomic effects interact with the adenosine receptor activity intracellularly or via a direct interaction at the adenosine receptor site. This may cause the improvement on AMP-AHR up to $26 \mathrm{~h}$, with an effect that decreases in time, as found for the decrease of protection from 2 to $14 \mathrm{~h}$, and up to $26 \mathrm{~h}$ in this study. Furthermore, adenosine induces plasma exudation and bronchial blood flow increase that are associated with the local vascular effects of microvascular leakage and oedema of the airway wall that have been described as factors of AHR $[2,26]$. These vascular events may be reduced by ICS, with FP, in particular, being a potent agent to induce a vasoconstrictive effect $[22,25]$. In addition, it has previously been stated that FP decreases microvascular leakage and airway mucosal blood flow [2, 27]. These effects together may contribute to the prolonged protection by FP up to $26 \mathrm{~h}$ on AMP-induced bronchoconstriction in the present study. However, the exact mechanisms behind this duration of effect of acute ICS-induced inhibition on AMP-AHR needs further study.

This study may have some limitations. First, the doseresponse for the activity of FP administered up to $26 \mathrm{~h}$ prior to AMP challenge was not determined in this study and therefore it is still unclear whether lower FP doses may cause similar improvement in AMP-PC20. However, a recently published study demonstrated a dose-dependent effect after $2 \mathrm{~h}$, using FP at either 100, 250 or $1,000 \mu \mathrm{g}$ [8]. Thus, the protection by inhaled FP appears to be a topical effect rather than an effect due to systemic exposure and hence lower doses might also be effective 14 and $26 \mathrm{~h}$ after inhalation. Secondly, only FP was studied. Other types of ICS could have been used to demonstrate the same duration of effect. Although protection on AMP-induced bronchoconstriction has been shown when single doses of beclomethasone $2,000 \mu \mathrm{g}$ or budesonide $1,600 \mu \mathrm{g}$ were administered $2 \mathrm{~h}$ prior to AMP challenge, this may not have similar results when studying duration of action in this model [28]. Thirdly, these single-dose effects of ICS towards AMP challenge may be influenced by the increasing osmolarity of the inhaled doubling concentrations of solutions, which has been shown to have an affect on the AHR in asthmatics [29]. Finally, the present study shows a model to assess the duration of effect of ICS for comparative studies on newly developed types of ICS, not for the purpose of dose regimen for clinical beneficial effects of a prolonged protection by a single dose of $1,000 \mu \mathrm{g}$ of FP. Despite the significant anti-inflammatory effect up to $26 \mathrm{~h}$ after FP administration, this model cannot be directly extrapolated to the clinical situation where ICS are given on a long-term basis.

In contrast to AMP challenge, the absence of a protective effect of FP on eNO up to $26 \mathrm{~h}$ after FP administration may indicate that these tests reflect different aspects of airway inflammation. Whether an ICS-induced anti-inflammatory effect on eNO release is dose-dependent, type of ICS dependent, time dependent or due to the mild disease of the included asthmatics has to be studied further. In addition, there is some evidence that it is dose dependent, as after $6 \mathrm{~h}$, single high-dose ICS treatment with nebulised budesonide $(8 \mathrm{mg})$, the eNO levels were reduced [10]. Furthermore, the percentage of sputum eosinophils may also be used to show an ICS-induced anti-inflammatory response, which was decreased $6 \mathrm{~h}$ after a single dose of budesonide [9]. These markers are all sensitive after hours of ICS treatment, whereas direct challenges are not [8]. These inflammatory markers and FEV1 appear to be less sensitive to reflect the direct activities of ICS-induced anti-inflammatory effects, as has been shown for AMP-AHR, which showed a directly proportional effect to the dose or timing of inhaled ICS used. Thus, taken together, these findings strengthen the view that AMP challenge is exceptionally sensitive to the topical effects of ICS.

In conclusion, a single dose of $1,000 \mu \mathrm{g}$ inhaled fluticasone propionate demonstrated a duration of action of up to $26 \mathrm{~h}$ by protection against adenosine- $5^{\prime}$-monophosphateinduced bronchoconstriction, without a significant effect on exhaled nitric oxide. This study further suggests that the anti-inflammatory response measured by an adenosine-5'monophosphate challenge is a sensitive tool for future comparative studies on duration of action of newly developed inhaled corticosteroids.

\section{References}

1. Lipworth BJ. Fortnightly review: modern drug treatment of chronic asthma. BMJ 1999; 318: 380-384.

2. Barnes PJ. Effect of corticosteroids on airway hyperresponsiveness. Am Rev Resp Dis 1990; 141: S70-S76.

3. Joos GF, $\mathrm{O}^{\prime}$ Connor B, Anderson $\mathrm{SD}$, et al. Indirect airway challenges. Eur Respir J 2003; 21: 1050-1068.

4. Polosa R. Adenosine-receptor subtypes: their relevance to adenosine-mediated responses in asthma and chronic obstructive pulmonary disease. Eur Respir J 2002; 20: 488496.

5. Van Schoor J, Joos GF, Pauwels RA. Indirect bronchial hyperresponsiveness in asthma: mechanisms, pharmacology and implications for clinical research. Eur Respir $J$ 2000; 16 : 514-533.

6. Van den Berge M, Meijer RJ, Kerstjens HA, et al. PC(20) adenosine $5^{\prime}$-monophosphate is more closely associated with airway inflammation in asthma than PC(20) methacholine. Am J Respir Crit Care Med 2001; 163: 1546-1550.

7. Prosperini G, Rajakulasingam K, Cacciola RR, et al. Changes in sputum counts and airway hyperresponsiveness after budesonide: monitoring anti-inflammatory response on the basis of surrogate markers of airway inflammation. J Allergy Clin Immunol 2002; 110: 855-861. 
8. Ketchell RI, Jensen MW, Lumley P, Wright AM, Allenby MI, $\mathrm{O}^{\prime}$ Connor BJ. Rapid effect of inhaled fluticasone propionate on airway responsiveness to adenosine $5^{\prime}$-monophosphate in mild asthma. J Allergy Clin Immunol 2002; 110: 603-606.

9. Gibson PG, Saltos N, Fakes K. Acute anti-inflammatory effects of inhaled budesonide in asthma: a randomized controlled trial. Am J Respir Crit Care Med 2001; 163: 32-36.

10. Kharitonov SA, Barnes PJ. Clinical aspects of exhaled nitric oxide. Eur Respir J 2000; 16: 781-792.

11. NHLBI/WHO Workshop Report 1995. Global strategy for asthma management and prevention. National Institutes of Health. National Heart, Lung, and Blood Institute, Bethesda, MD, updated April, 2002. Publication No. 95-3659. (Scientific information and recommendations for asthma programs. NIH Publication No. 02-3659).

12. Roca J, Burgos F, Sunyer J, et al. References values for forced spirometry. Group of the European Community Respiratory Health Survey. Eur Respir J 1998; 11: 1354-1362.

13. Sterk PJ, Fabbri LM, Quanjer PhH, et al. Standardized challenge testing with pharmacological, physical and sensitizing stimuli in adults. Eur Respir J 1993; 6; Suppl 16, 53-83.

14. Oosterhof Y, Koeter GH, De Monchy JGR, Postma DS. Circadian variation in airway responsiveness to metacholine, propranolol, and AMP in atopic asthmatic subjects. Am Rev Resp Dis 1993; 147: 512-517.

15. American Thoracic Society. Recommendations for standardized procedures for the online and offline measurement of exhaled lower respiratory nitric oxide and nasal nitric oxide in adults and children-1999. Am J Respir Crit Care Med 1999; 160: 2104-2117.

16. O'Connor BJ, Ridge SM, Barnes PJ, Fuller RW. Greater effect of inhaled budenoside on adenosine 5 '-monophosphateinduced than on sodium-metabisulfite-induced bronchoconstriction in asthma. Am Rev Resp Dis 1992; 146: 560-564.

17. Van den Berge M, Kerstjens HA, Meijer RJ, et al. Corticosteroid-induced improvement in the PC20 of adenosine monophosphate is more closely associated with reduction in airway inflammation than improvement in the PC20 of methacholine. Am J Respir Crit Care Med 2001; 164: $1127-1132$.

18. Kidney JC, Boulet L-P, Hargreave FE, Deschesnes F, Swystun VA, O'Byrne PM. Evaluation of single-dose inhaled corticosteroid activity with an allergen challenge model. J Allergy Clin Immunol 1997; 100: 65-70.

19. Lawrence M, Wolfe J, Webb DR, et al. Efficacy of inhaled fluticasone propionate in asthma results from topical and not from systemic activity. Am J Respir Crit Care Med 1997; 156: 744-751.

20. Rodrigo G, Rodrigo C. Inhaled flunisolide for acute severe asthma. Am J Respir Crit Care Med 1998; 157: 698703.

21. Engel T, Dirksen A, Heinig JH, Nielsen NH, Weeke B, Johansson SA. Single-dose inhaled budesonide in subjects with chronic asthma. Allergy 1991; 46: 547-553.

22. Johnson M. Development of fluticasone propionate and comparison with other inhaled corticosteroids. J Allergy Clin Immunol 1998; 101: S434-S439.

23. Derendorf H, Hochhaus G, Meibohm B, Mollmann H, Barth J. Pharmacokinetics and pharmacodynamics of inhaled corticosteroids. J Allergy Clin Immunol 1998; 101: S440-S446.

24. Ketchell RI, Clarke GW, Jensen MW, Vos TP, Allenby MI, $\mathrm{O}^{\prime}$ Connor BJ. Time course evaluation of the rapid effect of as single dose of inhaled fluticasone propionate on airway hyperresponsiveness to AMP in asthma (abstract). Am J Respir Crit Care Med 2003; A770: D55.

25. Mc Fadden ER. Inhaled glucosteroids and acute asthma; therapeutic breakthrough or nonspecific effect? Am J Respir Crit Care Med 1998; 157: 677-678.

26. Feoktistov I, Polosa R, Holgate ST, Biaggioni I. Adenosine A2B receptors: a novel therapeutic target in asthma? Trends Pharmacol Sci 1998; 19: 148-153.

27. Kumar SD, Brieva JL, Danta I, Wanner A. Transient effect of inhaled fluticasone on airway mucosal blood flow in subjects with and without asthma. Am J Respir Crit Care Med 2000; 161: 918-921.

28. Ketchell RI, Jensen MW, Clark GW, Allenby MI, $\mathrm{O}^{\prime}$ Connor BJ. Rapid effect of single dose inhaled glucocorticosteroid on airway hyperresponsiveness to AMP in asthma is not molecule dependent (abstract). Am J Respir Crit Care Med 2003; A770: D54.

29. Anderson S, Smith CM. Osmotic challenges in the assessment of bronchial hyperresponsiveness. Am Rev Resp Dis 1991; 143: S43-S46. 